\title{
Maximizing Coverage, Reducing Time: A Usability Evaluation Method for Web-Based Library Systems
}

Shumaila Iqbal ( $\square$ shumaila.iqbal@riphah.edu.pk)

Riphah International University

Naveed Ikram

Riphah International University

salma Imtiaz

International Islamic University

Saima Imtiaz

International Islamic University

\section{Research Article}

Keywords: Usability, Coverage, Evaluation, Web Based Library Systems, Checklist, Experiment

Posted Date: January 5th, 2022

DOI: https://doi.org/10.21203/rs.3.rs-1151576/v1

License: (c) (i) This work is licensed under a Creative Commons Attribution 4.0 International License.

Read Full License 
Maximizing Coverage, Reducing Time: A Usability Evaluation Method for Web-Based Library Systems

\author{
Shumaila Iqbal ${ }^{1 *}$ \\ Dr. Naveed Ikram² \\ Dr. salma Imtiaz ${ }^{3}$ \\ Saima Imtiaz ${ }^{4}$
}

Faculty of Computing, Riphah International University, Islamabad, Pakistan ${ }^{1,2}$

Department of Computer Science and Software Engineering, International Islamic University, Islamabad, Pakistan ${ }^{3,4}$

shumaila.iqbal@riphah.edu.pk* $^{*}$

26 November 2021 


\title{
Maximizing Coverage,Reducing Time:A Usability Evaluation Method for Web-Based Library Systems
}

\author{
Shumaila Iqbal ${ }^{1 *}$, Naveed Ikram ${ }^{2}$, Salma Imtiaz ${ }^{3}$, and Saima Imtiaz ${ }^{4}$ \\ ${ }^{1,2}$ Affiliation, Department of Computing, Riphah International University, Islamabad, Pakistan \\ 3,4 Affiliation, Department of Computer Science and Software Engineering, International Islamic University, \\ Islamabad, Pakistan
}

\section{ABSTRACT}

\begin{abstract}
Usability of a Web Based Library Systems (WBLS) is a major quality attribute. Checklists have become common and easy method to evaluate the usability of these WBLS; however the available checklists support evaluation of general usability aspects of WBLS only. The domain specific usability aspects are required to maximize the usability for such systems. This research proposes and validates a checklist based usability evaluation method that supports the evaluation of general as well as specific usability aspects of WBLS. The usability evaluation checklist is proposed based on analysis of literature and data of a controlled experiment. The checklist is validated in comparison to the "Academic Library Website Evaluation Checklist" via another controlled experiment. The proposed checklist is applied to the WBLS of universities in Pakistan. The manual and statistical result shows that, the proposed usability evaluation checklist identifies more general and specific usability aspects. It is found that both the checklists are equally efficient while identifying the usability errors. The proposed checklist is beneficial for the academia as well as industry to evaluate the usability of WBLS to an optimal level.
\end{abstract}

keywords- Usability, Coverage, Evaluation, Web Based Library Systems, Checklist, Experiment

\section{Introduction}

Usability is a critical success factor of a Web Based Library System (WBLS). It is a quality attribute to assess the easiness of user interface with multi-dimensional attributes of usability being learn-ability, efficiency, memorability, low error rate and satisfaction ${ }^{1}, 2$. There exists different approaches to evaluate usability ${ }^{2}$ such as heuristic evaluation ${ }^{3}$, cognitive walk through ${ }^{4}$, formal usability inspections ${ }^{5}$, pluralistic walk through ${ }^{6}$ and checklists ${ }^{7}$ [9]. The metrics used to measure usability are diverse such as task completion time, error rates, subjective satisfaction, perceived workload, assessment of a work product's quality, feeling of enjoyment, questionnaires on ease-of-use etc. ${ }^{8,9}$. In this research, the checklist based usability evaluation method is adopted and measured. The usability in terms of effectiveness correspond to number of errors and efficiency i.e. time taken to complete the tasks. In the modern era, the use of WBLS and related technologies such as Next Generation Catalogue (NGC) and Online Public Access Catalogue (OPAC) have become widespread. The use of this phenomenon is becoming common with a view to remove the obstacles facing the libraries and enhance quick and easy information retrieval, ${ }^{10,1112}$. In WBLS, the quality of delivery of functionality to the library users mainly students and researchers, is the key factor affecting the performance of libraries. The easy and interactive user interface is an intermediary that bridges the WBLS and end users. Designing interface compelling its general functionality like all other web based systems and domain specific functionality of library systems is a core issue in designing WBLS ${ }^{13}$. This study performs the evaluation of the usability of WBLS of academic sector, where the end user concerns reflect the entire functionality including general and specific usability aspects of WBLS The paper is structured as follows. Section 2 provides the Literature Review. Section 3, describes the Methodology. Section 4, gives a detailed insight to the development of the Proposed Usability Evaluation Checklist. Section 5, presents the Validation. Section 6, focuses on the Experimental Results and Analysis. Section 7 elaborates the Findings and provides Discussion. Section 8 highlights the Threats to Validity and Conclusion and Future Work is given in Section 9. 


\section{Results}

To measure the effectiveness of the proposed checklist, Table 2 summaries and compares the usability errors identified by both checklists, which shows a significant difference between both checklists. The major difference found in the aspects of interaction and library services where proposed checklist has identified 30 and 21 usability errors while only 6 and 7 usability aspects are identified using the Academic Library Website Evaluation Checklist. For the usability aspect, aesthetics, proposed checklist has identified 8 errors but in contrast existing checklist is unable to identify any error. In the aspect of navigation (14), E-sources (10), and search results (10) proposed checklist has identified maximum usability errors as compared to existing checklist (4). Both the checklists identify same usability errors for the aspect of library content (15).

The independent sample t-test statistics is used to measure effectiveness and to determine the difference between two techniques. The results show that, the significant difference between mean of two checklists is 0.033 which is less than the significance level of 0.05 that depicts the significance difference in the identification of usability errors. The cumulative results present that the proposed checklist has identified

108 usability errors, while existing checklist identified 49 usability errors. Therefore the proposed checklist has more coverage of usability questions in each usability aspects as compared to the existing checklist. It also indicates that proposed checklist is more effective with maximum coverage of usability aspects i.e. interaction, navigation, aesthetics, library content, E-sources, library services, and search results.

using proposed checklist $(\mathrm{M}=15.43, \mathrm{SD}=7.0)$ and Academic Library Website Evaluation Checklist $(\mathrm{M}=7.74, \mathrm{SD}=4.62)$ conditions; $\mathrm{t}(12)=2.47, \mathrm{p}=0.033$. These results suggest that proposed checklist is an effective usability evaluation checklist. Specifically, the results suggest that proposed checklist results in identification of maximum usability errors.

To measure efficiency, the time taken by both checklists to evaluate the WBLS is compared. The result in Table 4 shows that proposed checklist took 27.8 minutes to find the usability errors, in contrast to Academic Library Website Evaluation Checklist, which consumed 27.6 minutes to find the usability errors. These results show that the rate of identifying usability errors per minute by both usability evaluation checklist is almost the same. Hence, it is concluded from the above discussion that the proposed checklist and the Academic Library Website Evaluation Checklist, both are efficient enough to identify the usability errors in equal time.

The statistical t-test for comparison of efficiency of proposed checklist and Academic Library Website Evaluation Checklist applied, which shows significance difference as 0.965 , which is greater than significance level 0.05 . It means that there is no significance difference in the efficiency of proposed checklist $(\mathrm{M}=0.690, \mathrm{SD}=0.465)$ and Academic Library Website Evaluation Checklist $(\mathrm{M}=0.695, \mathrm{SD}=0.556)$ conditions; $\mathrm{t}(78)=-0.44, \mathrm{p}=0.965$. The results suggest that both checklists $\mathrm{P}$ and $\mathrm{E}$ are equally efficient to identify the usability errors. The reason for these results may be that both checklists are easy to understand by the evaluators to identify the usability errors.

\section{Discussion}

This section will discuss results highlighting the main findings of the study.

(RQ1): the first question asked, "What is the level of coverage of usability aspects provided by different checklists in web based library systems?"

The analysis of results obtained from the first experiment reveals that, the identified level of coverage of usability aspects for WBLS evaluation includes, interaction, navigation, aesthetic, content, content presentation, consistency, accessibility, ads, charges, library content, E-sources, library services, smart searching and search results. Accordingly, the proposed usability evaluation checklist is comprehensive and optimal with maximum coverage of usability aspects including general and domain specific usability aspects under one checklist.

The use of the proposed checklist was unable to identify the aspect of error prevention an important aspect in Nielson heuristics. One of the reason can be that errors prevention is considered critical for data entry web-based applications, whereas WBLS mostly consist of search functionality.

(RQ2): "How effective and efficient the proposed checklist is with respect to providing coverage of optimal set of usability aspects?"

The result analysis through the comparative method and statistical analysis shows that the proposed checklist is more effective than Academic Library Website Evaluation Checklist due to its maximum identification of usability errors. Since each usability, aspect in proposed checklist is covered via optimum numbers of usability questions than the Academic Library Website Evaluation Checklist. Both the evaluation checklists are equivalent efficient. This may be because both checklists are easy to understand by the subjects, hence equal time is taken to perform a task. 


\begin{tabular}{|c|c|c|}
\hline Usability Aspects & Sub-Aspects & Usability Questions \\
\hline \multirow[t]{3}{*}{ Interaction } & help & Online help is provided \\
\hline & & The site provides appropriate feedback about what is searched for \\
\hline & interactivity & Contact us link provided \\
\hline \multirow[t]{6}{*}{ Navigation } & navigation & $\begin{array}{l}\text { Pages are easy to navigate (sitemap, path information, table of con- } \\
\text { tents/index, navigation through scrolling, flipping and searching, back to } \\
\text { homepage) }\end{array}$ \\
\hline & links & Links are identifiable (through colour or underline) \\
\hline & & Homepage link is on every page \\
\hline & & Links are closely associated with their reference \\
\hline & searching & Search result page is relevant to the searched term \\
\hline & & $\begin{array}{l}\text { User Can search library OPAC (Online Public Access Catalogue is an } \\
\text { online database of material held by the library) }\end{array}$ \\
\hline \multirow[t]{4}{*}{ Aesthetic } & $\begin{array}{l}\text { graphics and anima- } \\
\text { tion }\end{array}$ & $\begin{array}{l}\text { easy to read graphics in the site (images, audio/video, relevant animation, } \\
\text { flash technology, no watermarking) }\end{array}$ \\
\hline & & Graphics images are relevant to the context \\
\hline & interface design & The site is visually attractive \\
\hline & & Page layout is comprehensible \\
\hline \multirow[t]{6}{*}{ Content } & content accuracy & Information is accurate \\
\hline & & important features of the site easily recognizable \\
\hline & content completeness & Details about the organization provided \\
\hline & & Sufficient information presented to understand the focus \\
\hline & content currency & The site contains updated information \\
\hline & & Updated content satisfies the information need \\
\hline \multirow[t]{6}{*}{ content presentation } & content presentation & Content presented in sequential order (based on date, title etc.) \\
\hline & & Emphasize the highest priority of content \\
\hline & text & The text is easy to read in contrast to their background \\
\hline & & Text have standard font size (12-point print type) \\
\hline & titling and labelling & Titles are suitable to portray the content \\
\hline & language & language is user-friendly \\
\hline \multirow[t]{3}{*}{ Consistency } & consistency & pages layout is consistent \\
\hline & & Links are consistent with the objective \\
\hline & & Information is consistent with the mission statement \\
\hline Accessibility & accessibility & past content is accessible \\
\hline \multirow[t]{2}{*}{ miscellaneous } & ads & free of ads \\
\hline & charges & provide free access to information resources (user don’t need to pay) \\
\hline \multirow[t]{2}{*}{ library content } & library content & $\begin{array}{l}\text { Provide bibliographical details of main sources (books, research journals, } \\
\text { authors etc.) }\end{array}$ \\
\hline & & Copyright of information resources stated \\
\hline \multirow[t]{3}{*}{ E-sources } & E-sources & access to E-journals \\
\hline & & Access possible to open access resources \\
\hline & & Access possible to other web reference sites \\
\hline library services & library services & An option to ask from a librarian \\
\hline smart searching & smart searching & The site provides the facility of advance search \\
\hline \multirow[t]{2}{*}{ search results } & search results & Search result pages are relevant to the searched content \\
\hline & & Site response quickly in searching \\
\hline
\end{tabular}

Table 1. Proposed Usability Evaluation Checklist 


\begin{tabular}{|l|l|l|}
\hline No. & Proposed usability evaluation checklist & Academic Library Website Evaluation Checklist \\
\hline 1. & Contact us link provided & Given all the contact information \\
\hline 2. & $\begin{array}{l}\text { Pages are easy to navigate (sitemap, path information, } \\
\text { table of contents/index, navigation through scrolling, flip- } \\
\text { ping and searching, back to home page) }\end{array}$ & Web pages are easy to navigate \\
\hline 3. & Home page link is on every page & $\begin{array}{l}\text { Every page included way to turn the home page for the } \\
\text { site }\end{array}$ \\
\hline 4. & Links are closely associated with their reference & $\begin{array}{l}\text { All hyperlinks appropriate and relevant for an online ref- } \\
\text { erence desk }\end{array}$ \\
\hline 5. & $\begin{array}{l}\text { easy to read graphics in the site (images, audio/video, } \\
\text { relevant animation, flash technology, no watermarking) }\end{array}$ & The graphics and texts are most clear and easy to read \\
\hline 6. & $\begin{array}{l}\text { User Can search library OPAC (Online Public Access Cat- } \\
\text { alogue is online database of material held by the library) }\end{array}$ & An option to search a library's OPAC \\
\hline 7. & Copy right of information resources stated & Copyright status are clearly stated \\
\hline 8. & access to E-journals & Hyperlinks to e-journals and databases \\
\hline 9. & Access possible to other web reference sites & Hyper links to other web reference sites \\
\hline 10. & An option to ask from librarian & An option to request reference assistance \\
\hline 11. & Site response quickly in searching & Server appear to be fast \\
\hline
\end{tabular}

Table 2. Common Usability Aspects between Both Checklists for Effectiveness Analysis

\begin{tabular}{|l|l|l|}
\hline Usability aspect & $\begin{array}{l}\text { Proposed usabil- } \\
\text { ity evaluation } \\
\text { checklist }\end{array}$ & $\begin{array}{l}\text { Academic Library } \\
\text { Website Evalua- } \\
\text { tion Checklist }\end{array}$ \\
\hline Interaction & 30 & 6 \\
\hline Navigation & 14 & 9 \\
\hline Aesthetic & 8 & 0 \\
\hline Library Content & 15 & 15 \\
\hline E-Sources & 10 & 8 \\
\hline Library Services & 21 & 7 \\
\hline Search Results & 10 & 4 \\
\hline total & 108 & 49 \\
\hline
\end{tabular}

Table 3. Result Analysis for Effectiveness of Both Checklists

\section{Threats to Validity}

To minimize internal validity threat, the selected WBLS are chosen from Pakistan, which also have open access. The subjects are students of software engineering at undergraduate level who have knowledge of HCI. Training is given to all subjects to remove biasness and introduce them to the method.

To minimize the probability of external threats, the subjects are selected from multiple universities in Pakistan. The sample is independently and randomly selected, to ensure balanced mix of individual capability. The subjects are asked to perform the experiment in a well-equipped computer lab, where availability of computers, internet and electricity assures the external validity.

The most common conclusion validity threat is reduced by critically comparing the results of the subjects with expert results in first experiment in order to identify the true usability errors. Furthermore, the statistical t-test is used to compare the efficiency and effectiveness of both checklists, and determine the statistical significance of the results.

To satisfy the construct validity, this research has developed the interim checklist by considering all usability checklist with the general usability aspects that are sifted with the questions of OPAC and NGC evaluation checklist and guidelines proposed by heuristic evaluation. Moreover the usability experts carried out the validation of checklist.

\section{Methodology}

The process in Figure 1, presents an overview of proposed method for usability evaluation checklist. It is designed to address the limitations stated above in existing evaluation checklists for WBLS. The result of the process is to develop an effective 


\begin{tabular}{|l|l|l|}
\hline & $\begin{array}{l}\text { Proposed usabil- } \\
\text { ity evaluation } \\
\text { checklist }\end{array}$ & $\begin{array}{l}\text { Academic Library } \\
\text { Website Evaluation } \\
\text { Checklist }\end{array}$ \\
\hline $\begin{array}{l}\text { Average time } \\
\text { in minutes }\end{array}$ & 27.8 & 27.6 \\
\hline
\end{tabular}

Table 4. Results Obtained for Efficiency Analysis of Both Checklists

and efficient usability evaluation checklist that maximizes the coverage of usability including mgeneral and specific usability aspects of WBLS.

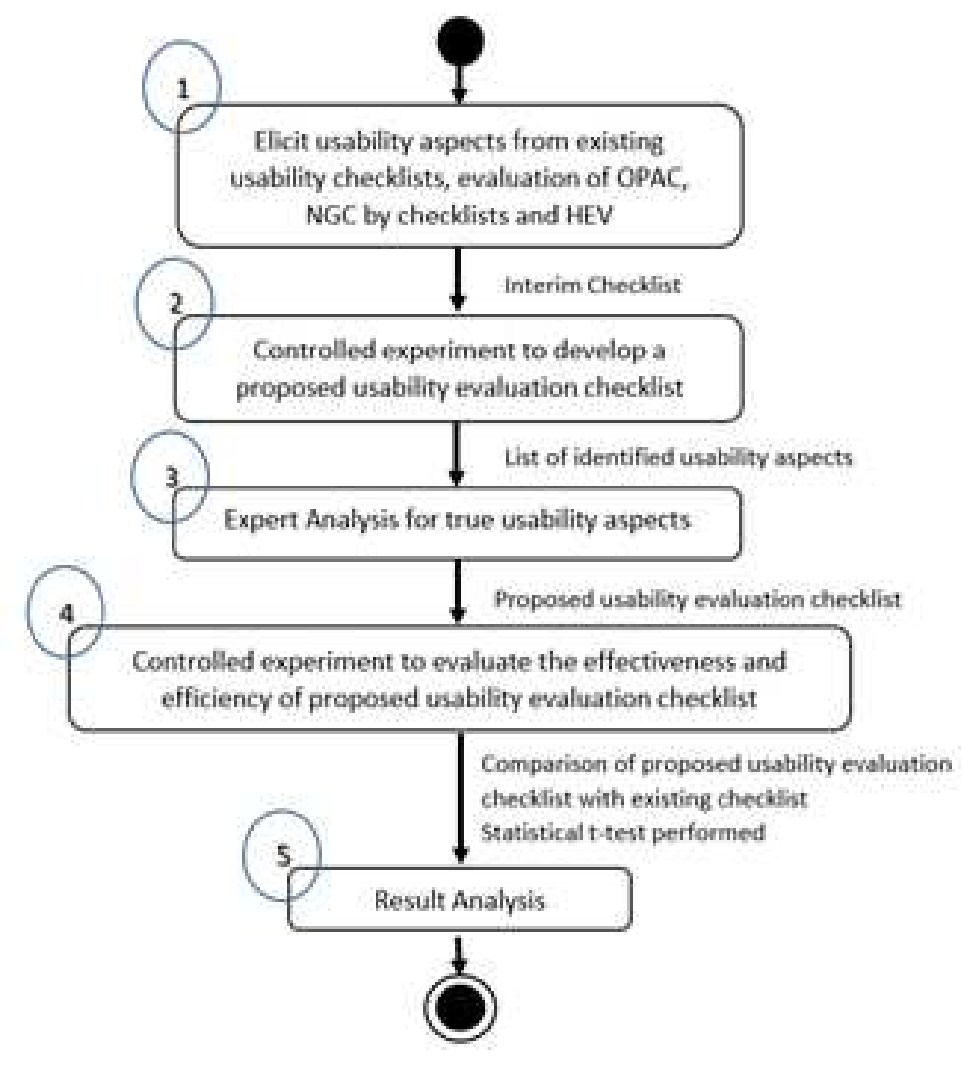

Figure 1. Research Methodology.

The research questions of the study are:

- RQ1: What is the level of coverage of usability aspects provided by different checklists in web-based library systems?

- RQ2: How effective and efficient the proposed checklist is with respect to providing coverage of optimal set of usability aspects?

The questions are answered by following multiple steps described in detail below.

- In step 1, all the usability aspects from the existing checklists are elicited. Moreover, this study relied on elicitation of specific usability aspects from the checklist based and heuristic evaluation based usability aspect from OPAC and NGCs. All the elicited usability aspects general and specific are integrated to form an interim checklist.

- In Step 2, first controlled experiment is conducted using interim checklist to evaluate 5 selected WBLS. The purpose of this step is to develop a checklist of optimal set of usability aspects general and specific that are required for evaluation of WBLS. 
- In step 3, to eliminate the ambiguity and false results, the identified usability aspects are compared to the usability aspects identified by usability experts. In doing so, the usability aspects (general and specific) that really exists in WBLS are determined. These true usability aspects are used to create a proposed usability evaluation checklist.

- In steps 4, second controlled experiment is performed to evaluate the effectiveness and efficiency of proposed checklist in comparison to existing optimal checklist known as Academic Library Website Evaluation Checklist.

- In step 5, the results obtained are analysed. The statistical t-test is applied to analyse the effectiveness and efficiency of proposed usability evaluation checklist.

\section{Development Phase of Checklist}

This section describes the development of usability evaluation checklist. It discusses how the usability aspects are elicited and integrated from the existing literature and then how they are refined to develop optimal usability evaluation checklist reflected as interim checklist..

\subsection{Interim checklist}

The existing literature is reviewed to capture all the usability aspects in order to develop an interim checklist as shown in Table 5. Usability aspects general and specific to the WBLS domain are identified through existing usability evaluation checklist of WBLS, OPAC and NGC evaluation.

The interim checklist consists of eighty-two most identified usability questions; assembled into fourteen main aspects. General usability aspects that are most commonly found in literature are interaction, navigation, aesthetic, content, content presentation, consistency, accessibility and error prevention. However, Ads free sites, free access of information, audience, number of hits responsiveness and tool assistance like PDF, seldom addressed usability aspects that exist in literature. The domain specific usability aspects as library content, E-sources, library services, smart searching and search results are extracted from the checklist based and heuristic based evaluation of OPAC and NGC. Each usability aspects contains different relevant questions to collectively evaluate the particular aspect. The usability questions are formulated in such a way that firmly indicates and guides the explicit usability error in WBLS.

\subsection{Development of Proposed Usability Evaluation Checklist}

The goal of development is to construct a usability evaluation checklist that satisfies the optimal and comprehensive set of usability aspects. A control experiment ${ }^{14}$ is performed to answer research question (RQ1). The participants used the interim checklist to evaluate the WBLS of five universities in Pakistan. A total of 86 subjects participated in the experiment. The participants are divided into group of five making a total of 430 subjects. Each group used the interim checklist and task scenarios on a different WBLS. The subjects of the experiment are chosen from students taking course of Human Computer Interaction, all being in the third year of bachelor in software engineering program. The participants are first given a training session of 30 minutes about the technique they are to use. The participants then use the technique on the assigned WBLS within an hour. The results on interim checklist obtained in the form of "Yes" and "No", where "Yes" represent the existence of usability aspect and "No" represent the non-existence of usability aspects formally known as usability error. The evaluation criteria with fourteen usability aspects are interaction, navigation, aesthetics, content, content presentation, consistency, accessibility, error prevention, miscellaneous, library content, E-sources, library services, smart searching and smart results. The obtained results are measured by calculating the ratio between no of usability errors found per total no of usability errors that exist. The total number of usability errors are identified from expert of the field prior to execution of the experiment.

Table 6 presents the identified true usability aspects ranked as high $(>=70)$, Medium $(>=50)$ and Low $(<50)$ classifications. Following the ranking criteria, it also illustrates the identified usability aspects under defined categories. The results show that the interaction (71\%), aesthetic (72\%), consistency (79\%), library content (78\%) and E-sources (80\%) are highly identified usability aspects in WBLS to enhance it usability. Whereas Navigation, content, content presentation, accessibility, Ads free sites, free access of information, audience, number of hits responsiveness and tool assistance like PDF are frequently identified. The usability aspect of error prevention and library services is rarely reported during evaluation.

In the analysis of the specific usability aspects, the result shows that E-sources is ranked high during evaluation showing importance of access to E-journals, open access journals and web references to research libraries. Another domain specific aspect library content is also ranked high representing the importance of bibliographical details of book, journals, authors and copyright features.

The aspect of library services has least count, which includes features of membership, online librarian assistance, printing facility, and RSS feed. 


\begin{tabular}{|c|c|c|}
\hline Usability aspects & Sub-Aspects & Usability Questions \\
\hline \multirow[t]{6}{*}{ Interaction } & Help & FAQ section available to answer user's questions \\
\hline & & Online help provided in the site \\
\hline & & Site provides appropriate feedback about what is searched for \\
\hline & interactivity & Allow user to send feedback \\
\hline & & Allow user to comment on the site \\
\hline & & Contact us link provided on the site \\
\hline \multirow[t]{11}{*}{ Navigation } & Navigation & $\begin{array}{l}\text { Pages are easy to navigate (sitemap, path information, table of contents/index, navigation through scrolling, flipping and searching, back } \\
\text { to home page) }\end{array}$ \\
\hline & & All provided links in site are working (no dead links) \\
\hline & & User can easily escape from undesired situation (back button, undo function, cancel/end program command) \\
\hline & Shortcut & Shortcuts available in the site (bookmarks, table of content etc.) \\
\hline & Searching & Internal search engine available to search library site \\
\hline & & Search result page is relevant to the searched term \\
\hline & & Allow user to search the library OPAC (Online Public Access Catalogue is online database of material held by the library) \\
\hline & Links & Links are identifiable (through color or underline) \\
\hline & & Homepage link is on every page \\
\hline & & Links are closely associated with their reference \\
\hline & & Visited and unvisited links are clearly identifiable \\
\hline \multirow[t]{6}{*}{ Aesthetic } & Interface design & Site is visually attractive \\
\hline & & Page layout is comprehensible \\
\hline & & Site is easy to use \\
\hline & Graphics and animation & easy to read graphics in the site (images, audio/video, relevant animation, flash technology, no watermarking) \\
\hline & & Graphics images are relevant to the context \\
\hline & & Site provides ALT tag for images (alternate text for an image, if the image cannot be displayed) \\
\hline \multirow[t]{9}{*}{ Content } & Content accuracy & Site contains accurate information \\
\hline & & Pages are free of irrelevant information \\
\hline & & Most important features of the site easily recognizable \\
\hline & Content currency & Site contains updated information \\
\hline & & Updated content satisfy the information need \\
\hline & & Shows the date/time the site was last updated \\
\hline & Content completeness & Details of organization provided in the site \\
\hline & & Sufficient information presented to understand the particular focus \\
\hline & & Unrelated information is explained in the site \\
\hline \multirow[t]{11}{*}{ Content presentation } & Text & Text have margin around \\
\hline & & Text is easy to read in contrast to their background \\
\hline & & Text have standard font size (12 point print type) \\
\hline & Titling and labeling & Titles are suitable to portray the content \\
\hline & & Clearly defined areas are not labeled (search, login etc.) \\
\hline & & Technical terms are not used to the title label \\
\hline & language & Site language is user-friendly \\
\hline & presentation & Content presented in sequential order (based on date, title etc.) \\
\hline & & Information is presented in different formats (full text, abstract) \\
\hline & & Highest priority of content is emphasized \\
\hline & Date and time & Date presented in international format (YYYY-MM-DD) \\
\hline \multirow[t]{3}{*}{ Consistency } & Consistency & pages layout is consistent \\
\hline & & Links are consistent with objective \\
\hline & & Information is consistent with mission statement \\
\hline accessibility & Accessibility & Loading/downloading speed is high \\
\hline & & past content is accessible \\
\hline Error prevention & Error prevention & Site allow user to recover from error (cancel operation, return to original) \\
\hline & & Site gives alert message to prevent from error \\
\hline & & Error prevention message reveals the description of the error \\
\hline Misc. & Ads & Site is free of ads \\
\hline & Charges & Site provide free access to information resources (user don't need to pay) \\
\hline & Audience & Audience of the page stated (computer science, electrical engineering, BBA etc.) \\
\hline & No of hits & Site shows the number of visitors in specified period of time \\
\hline & Responsiveness & Site is responsive to (libraryname.com or www.libraryname.com) \\
\hline & Tool assistance & Essential software is accessible from the site (like PDF etc.) \\
\hline Library content & Library content & Site shows bibliographical details of main sources (books, research journals, authors etc.) \\
\hline & & Copyright of information resources stated \\
\hline E-sources & E-sources & Site allow access to E-journals \\
\hline & & Access possible to open access resources \\
\hline & & Access possible to other web reference sites \\
\hline Library services & Library services & Site allow user to ask from librarian \\
\hline & & Printing service available to user \\
\hline & & $\begin{array}{l}\text { RSS feed is provided (Really Simple Syndication useful for keeping update on your favourite area through a feed like in blogs, newsletters, } \\
\text { and podcasts) }\end{array}$ \\
\hline & & Site allow user to register as a member of the site \\
\hline Smart searching & Smart searching & Site provide facility of advance search \\
\hline & & Facilitate the feature of auto correct/complete in searching \\
\hline & & provide the facility of the spell checker in the site \\
\hline & & provide an age appropriate "safe search" feature \\
\hline & & Site is able to handle "natural language" queries \\
\hline & & Site is able to retain queries from previous searches (search history) \\
\hline Search results & Search results & Search result pages are relevant to the searched content \\
\hline & & Site response quickly in searching \\
\hline & & Allow user to export the records \\
\hline & & Site allow user to refine the search queries \\
\hline & & $\begin{array}{l}\text { The site provides the faceted navigation? (Library catalogues should be able to display the search results as a set of categories, such as } \\
\text { subject terms, dates, languages, availability, formats, locations, etc.) }\end{array}$ \\
\hline & & Site gives recommendation for related material \\
\hline & & Site provide facility of sharing the search records (social media interaction) \\
\hline & & Provides the facility of saving the search records \\
\hline & & Site gives recent search page results \\
\hline & & The site is able to prioritize the search results? \\
\hline
\end{tabular}




\begin{tabular}{|l|l|l|}
\hline High usability aspects & Medium usability aspects & Low usability aspects \\
\hline Interaction (71\%) & Navigation (64\%) & Error Prevention (49\%) \\
\hline Aesthetic (72\%) & Content (68\%) & Library Services (48\%) \\
\hline Consistency (79\%) & Content Presentation (69\%) & \\
\hline Library Content (78\%) & Accessibility (69\%) & \\
\hline E-Sources (80\%) & Miscellaneous (66\%) & \\
\hline & Smart Searching (56\%) & \\
\hline & Search Results (54\%) & \\
\hline
\end{tabular}

Table 6. Identified Level of Coverage of Usability Aspects

For development of the proposed usability evaluation checklist, each usability question under each particular aspect is ranked by following above defined high, medium and low ranking criteria. The proposed usability evaluation checklist represented in Table 1, consist of usability questions, which resulted as high $(\leq 70)$ under each usability aspects.

The result shows that the identified level of coverage of usability aspects of a WBLS evaluation includes, interaction, navigation, aesthetic, content, content presentation, consistency, accessibility, ads, charges, library content, E-sources, library services, smart searching and search results. Accordingly, the proposed usability evaluation checklist is comprehensive and optimal with maximum coverage of usability aspects (general and domain specific) under one checklist.

\section{Evaluation of Proposed Usability Evaluation Checklist}

The goal of the evaluation is to assess the applicability and effectiveness of the proposed checklist, in an academic context. A controlled experiment is conducted to answer research question (RQ2), which measures the general and domain specific usability aspects of two WBLS of universities of Pakistan.

The proposed checklist is compared with existing checklist known as Academic Library Website evaluation checklist ${ }^{15}$. The mentioned checklist is chosen because it contains the general and specific usability aspects to evaluate online libraries. A Latin-squares experiment is designed, dividing the participants into two groups; each group is given task scenarios and both of the checklists, but receives different treatment in term of WBLS. Twenty subjects participated in each session resulting in forty samples for each WBLS. It is sufficient number of subjects required to perform meaningful statistical analysis. The participants are given a training session of 30 minutes about the technique they have to use. The participants are then given 2.5 hours to use the technique. T-test is applied on the results to ensure validity.

In this experiment, effectiveness and efficiency is measured. The effectiveness is calculated by the comparison of both evaluation checklists (proposed usability evaluation checklist and Academic Library Website Evaluation Checklist) with respect to the usability errors identified during evaluation. For this purpose, both checklists are compared to identify the common usability aspects, which are found as interaction, navigation, aesthetic, library content, E-sources, library services and search results.

Table 3 shows the common questions for effectiveness analysis under the matching usability aspects of both checklists. The results for effectiveness are collected using a quantitative rating system (ten-point scale), which signifies the level of existence of usability errors in particular WBLS. The rating scale (0-10) with rating (0-3) least existence, (4-6) for average existence and (7-10) for highest existence of usability aspects in WBLS, the usability errors are considered as usability aspects which have least existence in evaluation.

\section{Literature Review}

Multiple studies identify the usability aspects in different WBLS. These checklists include most of the general aspects that are common to any WBLS and used to evaluate any user interface. The other evaluation checklists and heuristics cover specific aspects only and are precise to the WBLS domain and its functionality. In the context of usability, studies evaluate aspects including the link contact us, user commenting or feedback and providing help to the user through online tutorials, search screen help, guide through documentation and FAQs that encourage the user to work with the site. ${ }^{12,15-26}$. Navigation empowers the usability with the features including site map and table of content ${ }^{?}, 12,17,18,20-23,25$. Informative, permanent and relevant links, return to a previous state or homepage link on every page increases the satisfaction of the user?,12,17,18,24,27-30. Most of the studies express the importance of the search aspect of the usability of a website ${ }^{12,15,17,18,24,25,29,31}$. The success of usability is dependent on attractive and well-organized homepage including images, colour, organization's logo, graphics and animation ${ }^{12,15,17,18,20,30}$. The appearance and pleasant user interface is a critical aspect of user satisfaction ${ }^{27,28,32}$. Data credibility that provides complete, relevant and updated information about the organization under the category about us link is 
also important ${ }^{12,15,17,18,20,24-26,30}$. Usability should be evaluated in terms of clear and understandable use of graphs, images, tables and diagrams with comprehensive viewpoint ${ }^{15,18},{ }^{12,17}$. Presenting logical and consistent content with readable text and use of appropriate and informative titles, labels, icon and buttons affect the user experience. The inconsistencies in presenting content in the site, terminology, design and navigation discourages the user ${ }^{12,17-19,24,25,29,30,32}$. The responsiveness of site with all browsers, its loading and downloading speed and accessibility with simple and responsive URL and error prevention helps in empowering usability ${ }^{12,15,17,18,24,25,29,30,32}$. Presenting the audience of the site, providing membership facility to the user, providing assistance via software tools like PDF, visitors count, ads free and other fun content contribute towards increased usability ${ }^{12,17,22,23,26}$. On the evaluation of specific usability aspects of library websites, studies highlight the importance of the copyright statement, bibliographical information of library content, separate display of new arrival and hyperlink to external resources, e-journals and open access resources ${ }^{15,19,22,23,26-28}$. The suggested aspects such as ask a librarian and reference assistance is rated higher including the RSS feed, instant messages and virtual help features of blogging and discussion forums ${ }^{15,26-29}$. Simple keyword searches and advanced search helps in acquiring the required search results more quickly and accurately ${ }^{19,21,27,28,33}$. Facilitating the library sites with a spell checker, auto-correct and auto-complete natural language facility to search and safe search feature to prevent visibility of undesired content to children as provided by Google also enhances the user experience. ${ }^{21-23,27,28}$. Studies also present sharing and exporting the searched content ${ }^{19,21,33}$, refine and modify to reset query at any stage of searching, ${ }^{19,20,29}$. Save the searched results and allow to download the library content $^{19}$, sort and prioritize the results per date, subject or keyword raise the usability of the site ${ }^{19,21}$. Display of search results with a poor organization, irrelevant ordering, grouping and prioritizing the results negatively effects the usability of the site $20,21,27,28$. The studies also specify the importance of recommendation of search results as per the number of hits on the library item or by the availability of the content, which helps the user to take quick results on their desired content ${ }^{26,27}$. Literature highlights that there does not exist an optimal set of usability evaluation aspects of WBLS in a single checklist that covers general as well as specific usability aspects. Summary of the observed literature is presented in Table 7 . Where $(\sqrt{ })$ shows that the particular aspect exists in the given literature (shows $>=50<=100 \%$ presence in literature), $(\times)$ represents that the particular aspect does not exist or $0 \%$ referred to by the particular literature and the symbol $(\approx)$ represents that the particular usability aspect is referred $>0<50 \%$ in the given literature.

\begin{tabular}{|c|c|c|}
\hline Aspects & Usability checklists & HEV,OPAC and NGC \\
\hline Interaction & $(\sqrt{ })$ & $(\approx)$ \\
\hline Navigation & $(\sqrt{ })$ & $(\approx)$ \\
\hline Aesthetic & $(\sqrt{ })$ & $(\approx)$ \\
\hline Content & $(\sqrt{ })$ & $(\approx)$ \\
\hline Content Presentation & $(\sqrt{ })$ & $(\approx)$ \\
\hline Consistency & $(\sqrt{ })$ & $(\times)$ \\
\hline Accessibility & $(\sqrt{ })$ & $(\approx)$ \\
\hline Error Prevention & $(\sqrt{ })$ & $(\approx)$ \\
\hline Miscellaneous & $(\sqrt{ })$ & $(\sqrt{ })$ \\
\hline Library Content & $(\approx)$ & $(\sqrt{ })$ \\
\hline E-Sources & $(\approx)$ & $(\sqrt{ })$ \\
\hline Library Services & $(\approx)$ & $(\sqrt{ })$ \\
\hline Smart Searching & $(\times)$ & $(\times)$ \\
\hline Search Results & $(\times)$ & $(\approx)$ \\
\hline
\end{tabular}

Table 7. Literature Analysis

\section{Author contributions statement}

This study was conceived and carried out by Shumaila.I as part of graduate thesis under the direct supervision of Dr. Naveed.I. Dr. Salma.I, and Dr. Saima.I.co-supervised the thesis and helped in preparation of the manuscript. Dr. Naveed.I reviewed the final manuscript.

\section{Additional information}

The authors do not have any financial and non-financial competing interests to report. 


\section{References}

1. Nielsen, J. Usability 101: Introduction to usability. https://www.nngroup.com/articles/usability-101-introduction-tousability/ (2012).

2. Nielsen, J. Usability engineering (Morgan Kaufmann, 1994).

3. Nielsen, J. \& Molich, R. Heuristic evaluation of user interfaces. In Proceedings of the SIGCHI conference on Human factors in computing systems, 249-256 (1990).

4. Polson, P. G., Lewis, C., Rieman, J. \& Wharton, C. Cognitive walkthroughs: a method for theory-based evaluation of user interfaces. Int. J. man-machine studies 36, 741-773 (1992).

5. Kahn, M. J. \& Prail, A. Formal usability inspections. In Usability inspection methods, 141-171 (1994).

6. Bias, R. G. The pluralistic usability walkthrough: coordinated empathies. In Usability inspection methods, 63-76 (1994).

7. Johnson, G. I. The usability checklist approach revisited. In Usability evaluation in industry, 179-188 (Taylor and Francis Ltd., 1996).

8. Hornbæk, K. \& Law, E. L.-C. Meta-analysis of correlations among usability measures. In Proceedings of the SIGCHI conference on Human factors in computing systems, 617-626 (2007).

9. Keevil, B. Measuring the usability index of your web site. In Proceedings of the 16th annual international conference on Computer documentation, 271-277 (1998).

10. Aruna, A. Online public access catalogue. DESIDOC J. Libr. \& Inf. Technol. 18 (1998).

11. Wilson, K. Opac 2.0: Next generation online library catalogues ride the web 2.0 wave! Online Curr. 21, 406-413 (2007).

12. Mohamadesmaeil, S. \& Koohbanani, S. K. Web usability evaluation of iran national library website. Collnet J. Sci. Inf. Manag. 6, 161-174 (2012).

13. Kiran, K. \& Diljit, S. Modeling web-based library service quality. Libr. \& Inf. Sci. Res. 34, 184-196 (2012).

14. Shadish, W. R., Cook, T. D., Campbell, D. T. et al. Experimental and quasi-experimental designs for generalized causal inference/William R. Shedish, Thomas D. Cook, Donald T. Campbell. (Boston: Houghton Mifflin,, 2002).

15. Konnur, P., Rajani, S. \& Madhusudhan, M. Academic library websites in bangalore city, india: an evaluative study. Libr. Philos. Pract. 8, 1-14 (2010).

16. Rai, N. Help mechanism systems offered in ir interface of e-journal database systems: A users' perception related to help mechanism in their information seeking tasks. Libr. Philos. \& Pract. (2014).

17. Mohamadesmaeil, S. \& Kohbanani, S. K. Web usability evaluation: An approach for evaluating the usability of national library websites in the persian gulf rim. Postcolonial Filipino Narrat. Fiction: Cogn. Character Analysis F. Sionil Jose's 5, 220 (2011).

18. Walia, P. K. \& UGC-SRF, M. G. Usability analysis of homepage of websites of national libraries in asia. Libr. Philos. Pract. 1 (2013).

19. Dai Luong, T. \& Liew, C. L. The evaluation of new zealand academic library opacs: a checklist approach. The Electron. Libr. (2009).

20. Khoo, M., Kusunoki, D. \& MacDonald, C. Finding problems: When digital library users act as usability evaluators. In 2012 45th Hawaii International Conference on System Sciences, 1615-1624 (IEEE, 2012).

21. Khoo, M. \& Hall, C. What would 'google 'do? users ' mental models of a digital library search engine. In International Conference on Theory and Practice of Digital Libraries, 1-12 (Springer, 2012).

22. Verma, N. K. \& Shukla, A. Usability analysis of central universities libraries websites of north-east india: An evaluative study. J. Adv. Res. Libr. Inf. Sci. 4, 37-41 (2017).

23. Verma, N. K. \& Shukla, A. Usability analysis of indian institutes of management libraries websites: An evaluative study. $J$. Adv. Libr. Sci. 5, 23-32 (2018).

24. Pant, A. Usability evaluation of an academic library website: Experience with the central science library, university of delhi. The electronic library (2015).

25. CLN, L. O. A. Usability evaluation of university library websites in south-south nigeria. Libr. Philos. Pract. 1-25 (2020).

26. Kumar, V. \& Yadav, S. B. How efficient are university library portals of nirf ranked indian universities?: An evaluative study. DESIDOC J. Libr. \& Inf. Technol. 40 (2020). 
27. Yang, S. Q. \& Wagner, K. Evaluating and comparing discovery tools: how close are we towards next generation catalog? Libr. hi tech (2010).

28. Yang, S. Q. \& Hofmann, M. A. Next generation or current generation? Libr. hi tech (2011).

29. Islam, M. \& Ahmed, S. Z. Measuring dhaka university students' perceptions of ease-of-use and their satisfaction with university library's online public access catalogue. Perform. Meas. Metrics (2011).

30. Aitta, M.-R., Kaleva, S. \& Kortelainen, T. Heuristic evaluation applied to library web services. New library world (2008).

31. Alkindi, S. \& Bouazza, A. An evaluation study of the navigation and search systems on two academic websites and google. The Int. Inf. \& Libr. Rev. 42, 50-61 (2010).

32. Madhusudhan, M. \& Ahmed, N. Evaluation of indian institutes of management library websites in india. World Digit. Libr. international journal 6, 49-72 (2013).

33. Hofmann, M. A. \& Yang, S. Q. “discovering” what's changed: A revisit of the opacs of 260 academic libraries. Libr. hi tech (2012). 